\title{
Giant Cell Reparative Granuloma of Maxilla
}

\author{
Abhay Gupta, Lecturer in E.N.T., Pravara Rural Hospital, Loni., \\ S. R. Agrawal, Professor and Head, Dept. of Otorhinolaryngology,
}

G. R. Medical College, Gwalior. M. P.

\section{Abstract}

Giant Cell Reparative Granuloma is a reparative process in mandible. A case of Giant Cell Reparative Granuloma of Maxilla in a 15 years old female is reported. Tumour is very rare in maxilla and more often is diagnosed as a giant cell tumour. The case is reported on account of its rarity in maxilla and dilemma in differentiating it from other giant cell lesions. Differentiation is only based on the clinical test histopathological examination.

Key Words

GCRG - Giant Cell Reparative Granuloma GCT - Giant Cell Tumour

USG - Ultrasonograph CTScan - Computerized Tomograph Scan

Its not common for an Otolaryngologist to confront solitary bone tumours of head \& neck, more so a GCT in his life time. Solitary bone tumours of the head and neck are not common. These bones develops in membrane. Uncommon appearance of GCT is reported in temporal and sphenoid bones of middle cranial fossa (WG McCluggagae et al 1995). These skull bones develop as long bones of body through process of endochondral bone formation where presence of GCT is well known. Of the different variant of GC tumours of head and neck, three types are common, giant cell reparative granuloma, Brown tumour of hyperparathyroidism and true GCT i.e osteoclastoma. Other Giant cell lesions are cortical fibrous defects, nonossifying fibroma, chondroblastoma, eosinophillic granuloma, solitary bone cyst etc. Differential diagnosis even with modern HP technique is very confusing due to almost similar microscopic feature. Only the battery of other test along with HPE helps in diagnosing GCT types. Due to presence of multinucleated Giant cells it has been coined as "GCT". In the GCT of head and neck commonest is that involving mandible and that of the maxilla is very rare.

\section{Case Report}

15 years old female presented with complaints of an oblong, diffuse painless swelling over right cheek, which was gradually increasing in size over a period of two and a half year. This swelling developed following a blunt injury over right half of face. There is no history of discharge from nose, blocking of nose, bleeding from nose. No history of tooth extraction, malaligned or missing tooth, or epiphora. The bony hard oblong swelling measuring $5 \times 8 \mathrm{cms}$, nontender, ill defined, temperature of the swelling was not raised, skin over swelling was normal, no pulsation neither palpable nor visible seen. Though there was no involvement of alveolar margin and tooth, hard palate on right side was bulging in oral cavity. No lymph node was palpable.

Routine hematological investigations revealed mild lymphocytosis (42\%). PNS X-ray (Waters view) revealed opacity in right maxillary antrum with indistinct superolateral borders. Elevation of floor of right nasal fossa was also a feature. No bone erosion was seen. Rest of the PNS were normal.

USG of right maxillary antrum showed thickened anterior wall echo measuring $32 \mathrm{~mm}$. A mass of mixed echogenecity with prominent non echogenic areas suggesting fluid was seen abutting the posterior wall echo.

CT scan done in standard $5 \mathrm{~mm}$. section, showed an irregular soft tissue shadow in right maxillary antrum with marked expansion of maxilla anteriorly. Interiorly expansion of alveolar margins involving hard palate up to midline is seen. Thinning of cortex with bony trabeculations traversing the mass was also seen. Bony 


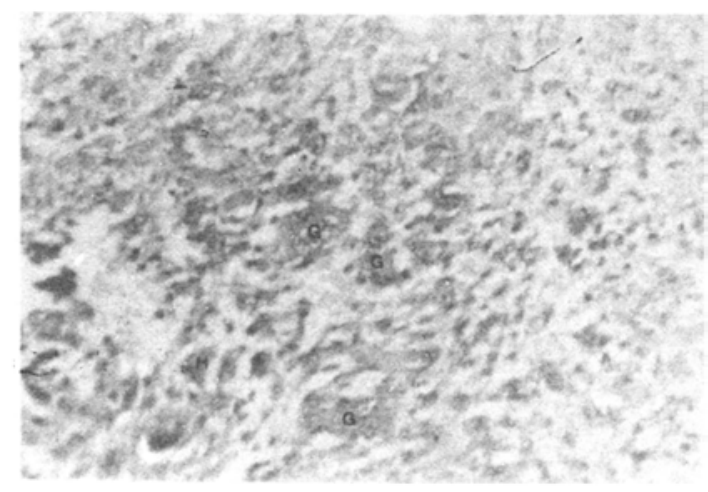

Fig. 1. Photomicrograph showing multiple unevenly scaottered Gaint Cells (a) with hemorrhage $(H)$.

boundaries were intact. On left side maxillary antrum showed a mass with soft tissue density suggesting antral polyp.

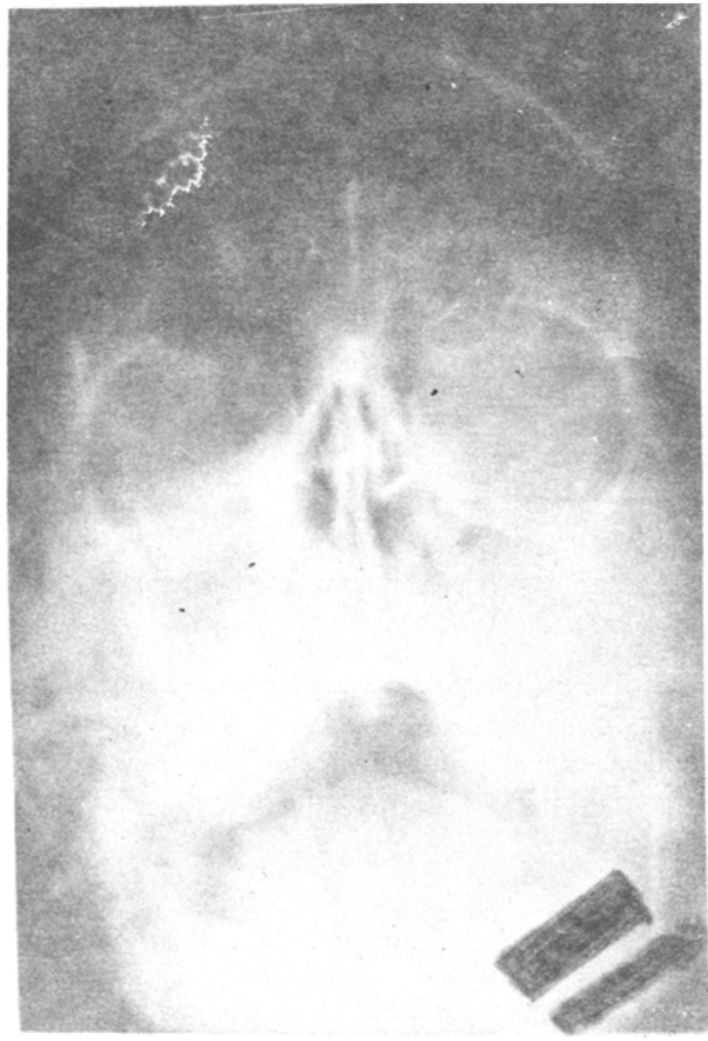

Fig. 2 X-ray showing expansion of Rt. Maxilla with haziness of Lt. Maxilla

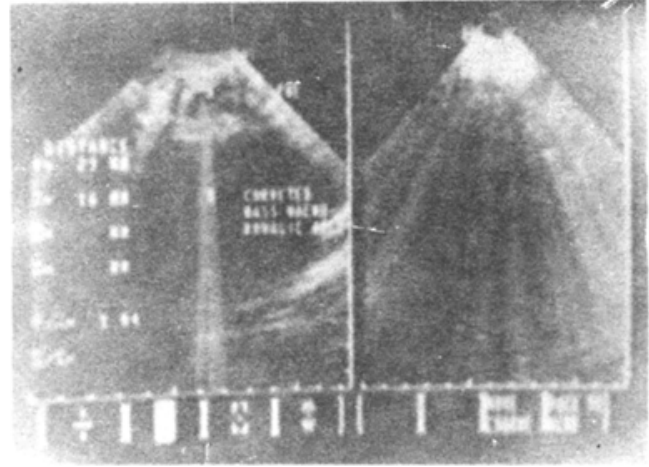

Fig 3. Ultrasonograph showing irregular anterior wall echo following surgery.

Patient was planned for Cald wel Luc's operation. On surgically opening the antrum resulted in profuse hemorrhage. Whole of the soft, reddish brown tissue was curretted out. Hemorrhage was so profuse that blood transfusion was required. Arterial hemorrhage from bony wall was stopped by pressure packing and cautery. Wall of antrum was lined with bone wax. Once hemostasis achieved, cavity was packed with Furacin tape gauge. Post operative period was without any hemorrhagic episode.

Histopathological examination of tissue revealed dense spindly fibroblast with multinuclear osteoclast like Giant cell unevenly distributed and clustered around the focal areas of hemorrhages. Tissue was highly vascular.

On follow up, recurrence was seen within 6 months and this was cured with repeat surgical excision. No recurrence was seen after 2 nd excision even after 1 year.

\section{Discussion}

The term giant cell reparative granuloma was coined by Jaffe (1958) to describe certain exclusively occurring tumours of the jaw bones. Following trauma, where osteoid deposition are seen along areas of destruction giving appearance of attempted repair. It involves tooth bearing area of jaw. It is more common in females of 2 nd-3rd decades and is related to hemorrhage in the bone marrow following trauma. Its divided into central and peripheral types according to origin from endosteal or periosteal surface. In skull sphenoid and temporal bones are more frequently 


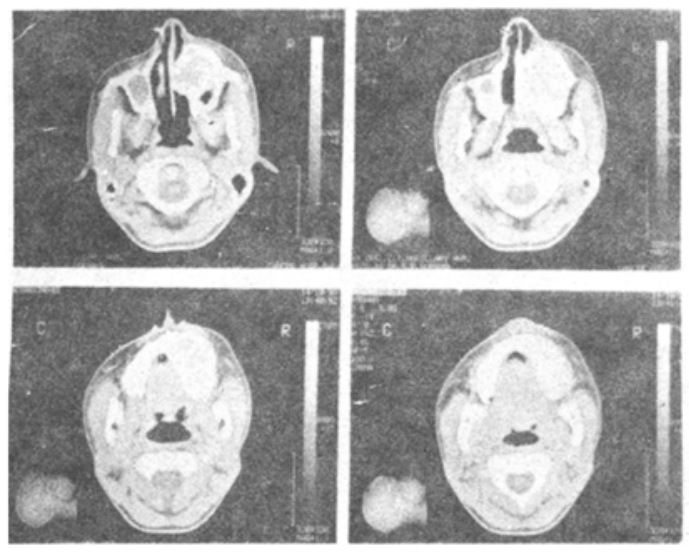

Fig. 4. C.T. Scan showing an expansion of Rt. Maxilla with a mass along with bony trabeculations travensing it. Expansion of of upper jaw is also seen on lt. side a simple benign mass is seen.

involved and only 15 cases had been encountered in each location? ${ }^{7}$ Rarely GCG have been reported on nasal septum, skull base, cranial vault and PNS (Quoted by Koay et al 1995).

Tallen et al (1994) in their retrospective study of Giant cell Granuloma during the period of 1970-1990, found only 18 advance cases involving jaw and out of which only 1 case involving maxilla. On reviewing literature we found that only six cases of giant cell reaparative granuloma involving maxilla has been reported in last five years. An unusual case was reported by Wise and Bridbord (1993), where multiple facial bones were involved. Fort et al (1990) reported a case of giant cell reaparative granuloma in 15 years, old girl following radiotherapy,

Friedman \& Pearlman (1968) said that giant cell reparative granuloma is a true neoplasm that produce bone destruction and does not arise as a reparative process. Also characteristic radiological behaviour of this lesion more closely resemble that of benign neoplasm. It has a tendency to be locally destructive and may take aggressive course despite being a benign disease. It presents as a painless swelling in the jaw displacing developing teeth and expanding the bone. Macroscopically its soft spongy, reddish brown, friable, highly vascular tissue mass replacing the bone and may look like a cyst or may have much less defined margins ${ }^{1}$.
Radiologically giant cell reparative granuloma presents as a lytic area which only rarely expands the bone and may contain numerous septae. CT Scan finding generally reflects a slowly expansile process with displacement and thinning of bony walls Differential diagnosis on CT scan includes ossifying fibroma, Brown tumour of hyperparathyroidism, True Giant cell tumour, nonossifying fibroma and osteoclastoma ; some times it may become difficult to differentiate it from malignant or infective lesion.

Microscopically lesion consist of fairly loose fibrillar stroma composed of small spindle shaped fibroblast with areas of hemorrhages extravasation and residual hemosiderin are readily seen in lipid laden histiocytes. Unevenly scattered small multinuclear giant cells giving it name GCT. Giant cells tend to aggregate around areas of hemorrhages.

Histopathologically there are numerous other lesions which also have osteoclast like multinuclear giant cells; these includes GC'T or true osteoclast, Brown tumour of hyperparathyroidism, nonossifying fibroma, ossifying fibroma, fibrous dysplasia, solitary bone cyst aneurysmal cyst etc.

Fibrous dysplasia and other odontogenic tumours and nonodontogenic tumours can be easily excluded on the basis of their histopathological appearance, clinical and radiological assessment. However, GCT or osteoclastoma and brown tumour of hyperparathyroidism have virtually identical histologic and radiologic features and closely resembles granulomas. Brown tumour of hyperparathyroidism can be eliminated by biochemical test and presence of similar lesion in other bones ${ }^{4}$. Differentiation between giant cell tumour and giant cell reaparative granuloma is very difficult and it has been proposed that two entities are essentially variant of same disease process modified by the age of patient and site of occurrence (Auclair et al 1988). These two lesions have following histopathological differentiating features;

1) The larger more rounded giant cell with greater number of nuclei in the GCT.

2) The much more common occurrence of fresh hemorrhages and hemosiderin deposits in the giant cell reparative granuloma. 
3) More uniform dispersal of giant cells in the GCT.

4) The more frequent production of osteoid or new bone in giant cell reparative granuloma.

5) More frequent inflammatory component in giant cell reparative granuloma.

6) The greater tendency for the nuclei to aggregate centrally in the giant cell of GCT.

7) The presence of foci of necrosis in the giant cell of GCT.

Accepted treatment for giant cell reparative granuloma is local excision with or without curettage. This cures about $80 \%$ of cases. The usual recurrence rate is $20 \%$. Nevertheless recurrence rate can be reduced by meticulous curettage and reexamination of the lesion for any remaining mass following hemostasis. Patient should be followed up for long duration. Any recurrence require additional curettage. Radiotherapy is also recommended for nonresectable and cases not amenable to the surgery. In some cases radioresistance has been reported (Wintrobe et al 1987), also there is always long term risk of sarcomatous changes associated with it.

In present case, presence of history of blunt trauma $2 \frac{1}{2}$ years back. Also patient was female in 2 nd decade. Histopathological finding showing presence of giant cells aggregating around the areas of hemorrhages and had uneven distribution. These all features suggested the diagnosis of giant cell reaparative granuloma of maxilla. Thus combination of age sex past history of trauma, painless swelling along with radiological and histopathological finding can be used to diagnose the giant cell reparative granuloma from other bonafide giant cell lesion of the upper jaw.

\section{References}

1) Auclair P. L., Guenin P, Krotochvil FJ, Sloler LJ, Ellis CL (1988) : A clinical and histopathological comparison of the central Giant cell granuloma \& Giant cell tumour. Oral Surg. Oral Medicine \& Oral Path.; 66: 197-208.

2) Friedberg SA. Eisentein R. Wallner $L j$ (1969): Giant cell lesion involving the nasal accessory sinuses. Laryngoscope; $79: 763-776$.

3) Friedman M\& Pearlman AW (1968): Benign giant cell tumour of bone, radiation dose for each type. Radiology; 91: 1151

4) Forte V, Shimotakahara S, Crysdale WS, Thorner P (1990): Recurring fiant cell granuloma at the site of previous radiation therapy. Jr. of Otolaryng. : Aug ; $19(9): 285-7$.

5) Huvos $A G$ (1991) : Giant cell tumour of the craniofacial bones. Giant cell reparative granuloma of jaw bone, cherubism Bone tumour diagnosis treatment and prognosis, Edited by Huvos AG, WB Saunders Co., Philadelphia, 2nd edition, Chap. 18, 469-70.

6) Jaffe HL (1953) : Giant cell reparative granuloma, traumatic bonecyst and fibrous dysplasia of the jaw bones. Oral Surgery; $6: 159-175$.

7) Koay CB, Whittel HB, Ryan RM, Lewis CS (1995): Giant cell reparative granuloma of the concha bullosa. Jr. of Laryngol. Otol. ; 109 : $555-58$

8) McCluggag WG, McBridge GB, Primrobe EJ, Cullan J, McNobae EJ, Bhanniha H, Fannin T (1995) : Giant cell tumour of temporal bone presenting as vertigo. Jr. of Laryngol, Otology ; 109-538-41.

9) Rhea JT. Weber Al (1983) : Giant cell granuloma of the sinuses. Radiology; $147 \cdot 13517$.

10) Tallen CM, Olson KD, McCaffery TV, Unni KK, Lund BA (1994): Advanced giant cell granuloma; a twenty years study. Otolary. Head \& Neck Surg. 110 (4) : 413-8.

11) Weber Al, Hayes E. Fabian R (1986): Giant cell granuloma of paranasal sinuses and nasal cavity. Annals of Oto Rhinolaryngol. ; $95: 541-42$.

12) Wiatrak B, Gluckman JL, Fabian RL, Wesseler TA (1987) : Giant cell reparative granuloma of ethemold sinuses. Otolary. Head \& Neck Surg. : 97 : 504-9.

13) Wise AJ, Bribord JW (1993) : Giant cell granuloma of facial bones. Ann. of Plastic Surg. ; June; 30 (6) : $564-8$. 